\title{
Pattern of musculoskeletal disorder among geriatric people residing old home
}

\begin{abstract}
Population ageing is a worldwide phenomenon that has recently challenged public healthcare systems. The knowledge of the burden of chronic musculoskeletal disorders in elders is still limited, particularly in the developing world. The purpose of this study was to assess pattern of musculoskeletal disorder among geriatric people residing old home. This was cross sectional study conducted among 100 people aged 60years and above residing Agargaon old home for a period of four months. Data were collected by pre tested structured questionnaires and in face to face interview. History of the study subjects as well as medical file was considered for diagnosis. Physical examination by final year physiotherapy students was done. Mean age of the respondents was $66.88 \pm 7.50$ years. Male and female distribution was almost equal. Almost $95 \%$ of the respondents suffered from musculoskeletal pain. Lower back pain, knee pain, shoulder+elbow+wrist+knee pain, hip pain and neck pain were common. Almost $36 \%$ of the respondents suffered from joint limitation. Knee joint limitation was common. Almost $84 \%$ of the respondents suffered from muscle weakness. About $95 \%$ of the respondents had no postural deformity. Seventy eight percent of the respondents faced difficulties in activities in daily living and walking was common. Knee osteoarthritis was common $(60 \%)$ followed by osteoporosis $(20 \%)$ and lumbar spondylosis $(13 \%)$. No statistical significant association was found between gender and musculoskeletal pain $(\mathrm{p}=0.538>0.05)$. It is concluded that prevalence of musculoskeletal disorder among geriatric people is high.
\end{abstract}

Keywords: pattern, musculoskeletal disorder, geriatric people, old home
Volume 5 Issue 4 - 2017

\author{
Tamanna Mir Lucky,' Sarker Shamima \\ Ahmed, ${ }^{2}$ Saima Binta Zaman,' Bakhtiar, ${ }^{3}$ \\ Apurba Biswas,' Nur Azad Choyan,' Abidur \\ Rahman,' Ropak Chandra Roy, ${ }^{4}$ Abu Saleh \\ Musa $^{5}$ \\ 'Physiotherapist, Center for Neuro \& Orthopedic Rehabilitation, \\ Bangladesh \\ ${ }^{2}$ Department of Community Medicine, Tairunnessa Memorial \\ Medical College \& Hospital, Bangladesh \\ ${ }^{3}$ Senior Research Officer, Exercise Physiology, Bangladesh Krira \\ Shikkha Protishtan, Bangladesh \\ ${ }^{4}$ Lecturer, Department of Physiotherapy, Gono Shasthaya Samaj \\ Vittick Medical College \& Hospital, Bangladesh \\ ${ }^{5}$ Paediatrics, Gono Shasthaya Samaj Vittick Medical College \& \\ Hospital, Bangladesh
}

Correspondence: Tamanna Mir Lucky, Physiotherapist, Center for Neuro \& Orthopedic Rehabilitation, Bangladesh, Tel 01721314195,Email gpabd17@gmail.com

Received: March 18, 2017 | Published: March 30, 2017

\section{Introduction}

Normal ageing is responsible for the finite life-span of the human race. It is important for the medical/health professional treating the elderly to know the difference between changes secondary to normal ageing and changes which occur as a result of disease. ${ }^{1}$ Lee KS (1991) also stated that there is ongoing research to increase our knowledge on the ageing process. Bangladesh is projected to be 1 of the 10 countries having largest elderly population. Present total population of Bangladesh is about 15 crore and 30lac will account about half of the world's total elderly population by 2025 along with other four Asian countries. ${ }^{2}$ According to the United Nations (UN), the proportion of older people (i.e. aged 60 and over) will triple over the next 40years and will account for more than $20 \%$ of the world's population by year $2050 .{ }^{3}$ In addition, it is estimated that one in five of the elderly population will be more than 80 years old in 2050 . The exponential increase of elderly people is mainly due to a rise in life expectancy, especially in the developing countries. According to the World Health Organization (WHO), one of the major disabling conditions among the elderly population is musculoskeletal (MSK) disorders. ${ }^{4}$ In 2003, the WHO's Global Burden of Disease study and the Bone and Joint Monitoring Project conducted a large report on the burden of MSK disorders through the existing data on the four major MSK conditions (OA, RA, OP, and low back pain (LBP)). ${ }^{5}$ From this report, it is clear that the burden of these major MSK conditions increases with age. From a health care perspective, the rising proportion and burden of older people demands that health care professionals increase their awareness of the health and disability of this particular population. Accordingly, there is a need to better understand the current magnitude and impact of MSK conditions from this growing population. The rapidly increasing elderly population is a new and important group in terms of social economic and changing cultural context. The assessment of health status requires the integration and interpretation of at least musculoskeletal condition, physical activity and life style. The older persons, in Bangladesh, are passing their days amidst the tender care and support mostly provided by their extended families without any remarkable backing from the national level. However, the situation is in transition as the family pattern gradually shifting towards the nuclear type due to the change in values, migratory tendency of their offspring and poverty. Geriatric problems are ignored in medical education and profession. There is a lack of information and research on elderly in health sector. There is scope for improving health and musculoskeletal problem of the elderly people.

\section{Materials and methods}

It was cross-sectional analytic study. The study was conducted among people aged 60years and above residing Agargaon old home. This study was carried out in Institute of Geriatric Medicine, Agargaon. This study was conducted for a period of four months. The sample size was three hundred and eighty five, for the time and economic constraints it was taken as 100 . No sampling technique was applied because all geriatric people was considered as sample. A pre-tested structure questionnaire was used to collect data. Data were collected by pre tested structured questionnaires and in face to face interview. History of the study subjects as well as medical file was considered for diagnosis. Physical examination by final year physiotherapy students was done. After data collection, data were sent to researchers, which was sorted, scrutinized by the researcher themselves by the selection criteria and then data were analyzed by personal computer by SPSS 
version 22.0 program. The open ended questions were grouped and categorized. Data were analyzed by descriptive statistics and inferential statistics.

\section{Results}

Table 1 shows mean age of the respondents was $66.88 \pm 7.50$ years More than half $(67 \%)$ of the study subjects belonged to 60-69years age group followed by $70-79$ years $24 \%$ and $\geq 80$ years $9 \%$ (Figure 1) (Table 2). Almost $95 \%$ of the respondents suffered from musculoskeletal pain. Among them $32 \%, 22 \%, 14 \%, 12 \%$ and $11 \%$ study subjects suffered from lower back pain, knee pain, shoulder+elbow+wrist+knee pain, hip pain and neck pain consecutively (Table 3 ). Almost $36 \%$ of the respondents suffered from joint limitation. Knee joint limitation was common (Table 4). Almost $84 \%$ of the respondents suffered from muscle weakness. Back muscle and thigh muscle were affected among $45 \%$ and $20 \%$ respondents (Table 5). Almost $95 \%$ of the respondents had no postural deformity. Few of the participants were found kyphosis, scoliosis and lordosis (Table 6). Almost 78\% of the respondents faced difficulties in activities in daily living. Walking was mentionable (Figure 2). Knee osteoarthritis was common (60\%) followed by osteoporosis $(20 \%)$, lumbar spondylosis (13\%), PLID $(6 \%)$ and rheumatoid arthritis (1\%) (Table 7). No statistical significant association was found between gender and musculoskeletal pain $(\mathrm{p}=0.538>0.05)$.

Male and female distribution were $52 \%$ and $48 \%$.

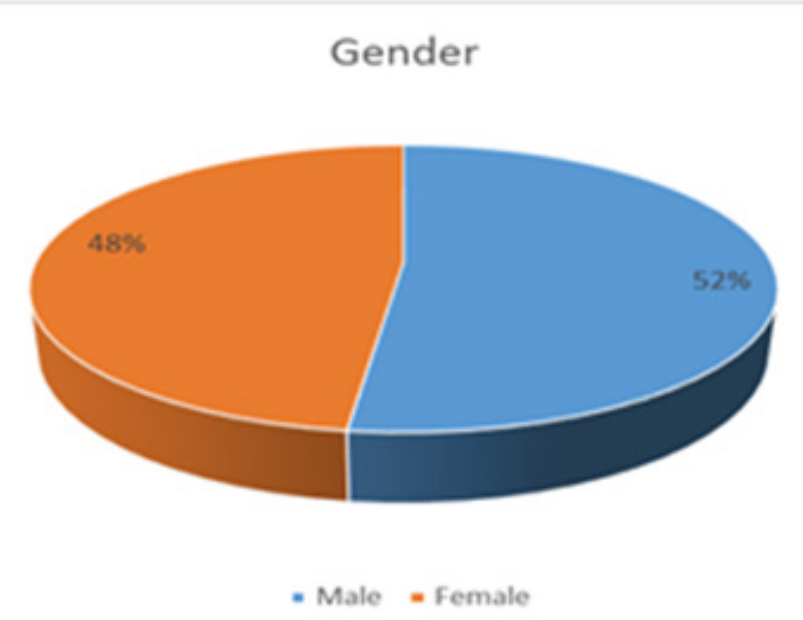

Figure I Gender distribution of the respondents $(n=100)$.

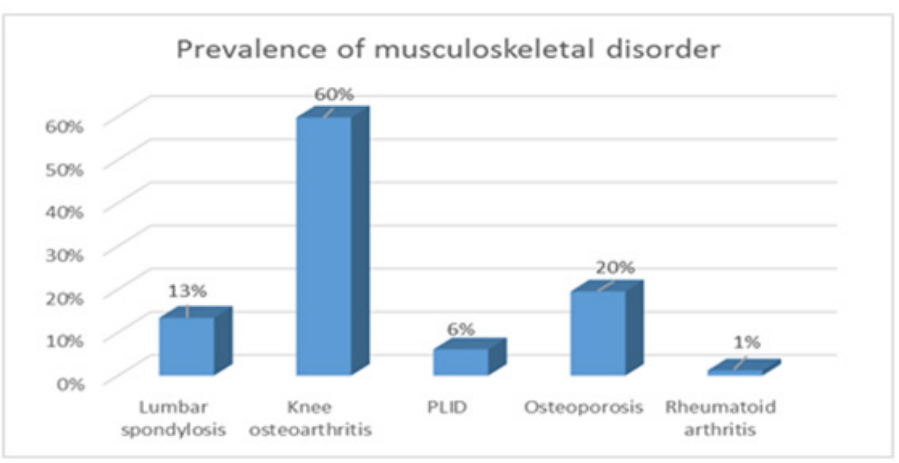

Figure 2 Prevalence of musculoskeletal disorder of the respondents $(n=82)$.
Table I Age group distribution of the respondents $(n=100)$

\begin{tabular}{lll}
\hline Age Group & Frequency & Percentage \\
\hline $60-69$ & 67 & 67 \\
$70-79$ & 24 & 24 \\
$\geq 80$ & 9 & 9 \\
Mean \pm SD & $66.88 \pm 7.50$ & \\
\hline
\end{tabular}

Table 2 Status of musculoskeletal pain in any part of body $(n=100)$

\begin{tabular}{lll}
\hline Musculoskeletal pain & Frequency & Percentage \\
\hline Yes & 95 & 95 \\
No & 5 & 5 \\
Total & 100 & 100 \\
$\begin{array}{l}\text { If yes, where was pain or discomfort? } \\
\text { (n=95) }\end{array}$ & \\
Hip & 12 & 12 \\
Knee & 22 & 22 \\
Shoulder+elbow+wrist+knee & 14 & 14 \\
Neck & 11 & 11 \\
Lower back & 32 & 32 \\
Shoulder & 2 & 2 \\
Wrist & 1 & 1 \\
Ankle & 1 & 1 \\
Total & 95 & 95 \\
\hline
\end{tabular}

Table 3 Status of joint limitation $(n=100)$

\begin{tabular}{lll}
\hline Joint limitation & Frequency & Percentage \\
\hline Yes & 36 & 36 \\
No & 64 & 64 \\
Total & 100 & 100 \\
If yes, which joint? (n=36) & & \\
Knee & 27 & 27 \\
Hip & 2 & 2 \\
Shoulder & 3 & 3 \\
Lower back & 2 & 2 \\
Elbow & 2 & 2 \\
Total & 36 & 36 \\
\hline
\end{tabular}


Table 4 Status of muscle weakness $(n=100)$

\begin{tabular}{lll}
\hline Muscle Weakness & Frequency & Percentage \\
\hline Yes & 84 & 84 \\
No & 16 & 16 \\
Total & 100 & 100 \\
If yes, which muscle? $(\mathrm{n}=84)$ & & \\
Back muscle & 45 & 45 \\
Thigh muscle & 20 & 20 \\
Neck muscle & 9 & 9 \\
Calf muscle & 6 & 6 \\
Elbow & 4 & 4 \\
Total & 84 & 84 \\
\hline
\end{tabular}

Table 5 Status of postural deformity $(n=100)$

\begin{tabular}{lll}
\hline Postural deformity & Frequency & Percentage \\
\hline Yes & 5 & 5 \\
No & 95 & 95 \\
Total & 100 & 100 \\
Type of postural deformity & & \\
Kyphosis & 2 & 2 \\
Scoliosis & 1 & 1 \\
Lordosis & 2 & 2 \\
Total & 5 & 5 \\
\hline
\end{tabular}

Table 6 Difficulties in activities in daily living $(n=100)$

\begin{tabular}{lll}
\hline Difficulties In ADL & Frequency & Percentage \\
\hline Yes & 78 & \\
No & 22 & \\
Total & 100 & 100 \\
Type of Difficulties in ADL & & \\
Lifting & 12 & 12 \\
Walking & 51 & 51 \\
Toileting & 7 & 7 \\
Griping & 8 & 8 \\
Total & 78 & 78 \\
\hline
\end{tabular}

Table 7 Association between gender and musculoskeletal pain

\begin{tabular}{llllll}
\hline \multirow{5}{*}{ Variables } & \multicolumn{2}{l}{$\begin{array}{l}\text { Musculoskeletal } \\
\text { pain }\end{array}$} & & & \\
\cline { 2 - 3 } & $\begin{array}{l}\text { Yes } \\
\mathbf{n}(\%)\end{array}$ & $\begin{array}{l}\text { No } \\
\mathbf{n}(\%)\end{array}$ & & p value \\
\hline Gender & & & & \\
Male & $49(49)$ & $3(3)$ & $52(52)$ & & \\
Female & $46(46)$ & $2(2)$ & $48(48)$ & & 0.135 \\
Total & $95(95)$ & $5(5)$ & $100(100)$ & & \\
\hline
\end{tabular}

\section{Discussion}

Geriatric people are an asset rather than burden if we properly take care because we have to step in that particular age group in certain period of life. Risk factors for falls include muscle weakness, a history of falls, use of four or more prescription medications, use of an assistive device, arthritis, depression, age older than 80years, and impairments in gait, balance, cognition, vision, and activities of daily living. The present study found high prevalence (95\%) of musculoskeletal pain among elderly people though sample size was not too large. Lower back pain, knee pain, hip pain and neck pain were common. One third of the patients suffered from joint limitation. Knee joint limitation was common. Almost $84 \%$ of the respondents suffered from muscle weakness. Seventy eight percent of the respondents faced difficulties in activities in daily living and walking was common. The study by Krishna swamy and Shanthi has also indicated that musculoskeletal problems like osteoarthritis, rheumatoid arthritis, myopathy secondary to hypothyroidism, cervical and lumbar spondylosis were the cause for falls in elderly. Neurological illnesses, which cause deterioration of sensorimotor function of muscle, contribute to falls. Musculoskeletal disease, physical disability or limited activity increased the risk of fall by two to four times. ${ }^{6}$ Many societies in Western Europe and Japan have ageing populations. While the effects on society are complex, there is a concern about the impact on health care demand. The large number of suggestions in the literature for specific interventions to cope with the expected increase in demand for long-term care in ageing societies can be organized under four headings: improve system performance; redesign service delivery; support informal caregivers; and shift demographic parameters. The annual growth in national health spending is not mainly due to increasing demand from ageing populations, but rather has been driven by rising incomes, costly new medical technology, a shortage of health care workers and informational asymmetries between providers and patients. A number of health problems become more prevalent as people get older. These include physical health problems, especially musculoskeletal disorder. ${ }^{7}$ It has been estimated that population ageing only explains 0.2 percentage points of the annual growth rate in medical spending of 4.3 percent since 1970. In addition, certain reforms to Medicare decreased elderly spending on home health care by 12.5 percent per year between 1996 and 2000. This would suggest that the impact of ageing populations on health care costs is not inevitable. ${ }^{8}$ Musculoskeletal disorders remain prevalent in the elderly population. Given the increasing proportion of elderly population in the world population and the burden of MSK diseases among the elderly people, efforts must be made to maintain their functional capacity for as long as possible through optimal primary and secondary health care. A total of 85 articles were included with 173 different prevalence estimates. Musculoskeletal disorders are common in the elderly population, but due to heterogeneity of the studies, no general estimate on the prevalence of MSK can be determined. Women report more often MSK pain than men. Overall, prevalence estimates either remain fairly constant or increase slightly with increasing age, but with a tendency to decrease in the oldest $(80+)$ people. ${ }^{9}$ From a health care perspective, the rising proportion and burden of older people demands that health care professionals increase their awareness of the health and disability of this particular population. Accordingly, there is a need to better understand the current magnitude and impact of MSK conditions from this growing population.

\section{Conclusion}

Musculoskeletal pain was found almost all of them. Limited 
range of movement due to arthritic change was also common which ultimately affects daily activities including self-care. In order to improve the health status of the elderly population it is important to carry out more studies in different areas to identify various factors that are related to musculoskeletal problem, which should lead to efforts to develop effective programmes in prevention as well as rehabilitation.

\section{Acknowledgements}

None.

\section{Conflict of interest}

The author declares no conflict of interest.

\section{References}

1. Lee KS, Owen RE, Choo PW, et al. The physiology of ageing. Singapore Med J. 1991;32(2):159-160.

2. Hossain MR. Aging in Bangladesh and its population projections. Pakistan Journal of Social Sciences. 2005;3(1):62-67.
3. World Population Ageing 2009. New York: United Nations; 2010. p. $1-82$.

4. Active Ageing-A Policy Framework. 2nd ed. USA: World Health Organization; 2002. p. 1-60.

5. Woolf AD. The bone and joint decade 2000-2010. Ann Rheum Dis. 2000;59(2):81-82.

6. Davis, Ross PD, Nevitt C, et al. Risk factors for falls and for serious injuries on falling among older Japanese women in Hawaii. $J$ Am Geriatr Soc. 1999;47:792-798.

7. Saltman RB, Dubois HFW, Chawla M. The Impact of Aging on Longterm Care in Europe and Some Potential Policy Responses. Int $J$ Health Serv. 2006;36(4):719-746.

8. Meara, Ellen, White, et al. Trends in medical spending on by age, $1963-$ 2000. Health Aff (Millwood). 2004;23(4):176-183.

9. Fejer R, Ruhe A. What is the prevalence of musculoskeletal problems in the elderly population in developed countries? A systematic critical literature review. Chiropr Man Therap. 2012;20(1):31. 